\title{
Estampa de Lope de Vega
}

\author{
Por Jean Camp
}

El 25 de Noviembre de 1962, en todos los países de lengua española, en todos los centros hispanistas del orbe, en todas las universidades, celebraremos con fervor el cuarto centenario del nacimiento en Madrid del "Monstruo de la Naturaleza" Félix Lope de Vega Carpio.

Adelantándose a este fausto acontecimiento, la Universidad de San Carlos, sus eminentes Rector y Decano de la Facultad de Letras, me brindan la ocasión de unir el homenaje de los hispanistas franceses al de los sabios y estudiosos de este país.

Por mi parte, intenté durante treinta años, presentar en los escenarios de París algunas lde las comedias másatípicas de nuestro poeta, cuya fama frangueaba tan difícilmentes las fronteras de su país y me es grato, hoy día, añadir una modesta estampa a los laureles que se van a brindar al ilustre dramaturgo.

Sólo al mencionar Lope de Vega, surge en seguida delante de los ojos la visión de un Madrid castizo, lindando el paseo del Prado, la calle de Atocha y este casco antiguo que ha resistido hasta hoy a la modernización niveladora.

Claro es que un Lope no podía nacer sino en Madrid para revelar al mundo ese madrileñísimo gracioso, burlón y poético que pocos equivalentes tiene en otras regiones de España.

Lope se,preciaba de ser de abolengo asturiana o montañés, es decir español viejo, sin mezcla de sangre judía y árabe, como lo pretendían también Quevedo y Calderón.

Pero de Madrid sacaba ese humor festivo y picaresco que debía esparcirse pronto en mil lindas escenas de sus comedias.

Allí nació en 1592, reinando el rey burócrata Felipe II, de un padre bordador de oro, artista por consiguiente él también de 
quien heredó Lope quizás aquellos bordados insuperables con que supo adornar los innumerables poemas que salieron de su pluma.

Tuvo un cuñado trancés que llevaba el nombre lindarnente sacado de una novela de caballería, Rosicler.

Turbulentas fueron la niñez y la juventud de Lope. Niño díscolo se escapó del hogar paterno a los doce años y sólo lograron agarrarle en Segovia. Si no, en vez de ser el gran dramaturgo que fue, quien sabe si no hubiera renovado la literatura picaresca, viviendo por su cuenta propia las aventuras de un Lazarillo de Tormes o de un Pablo de Segovia.

Después de Cervantes, estudió en la afamada Universidad de Alcalá, pero no pudo encontrar allí al Príncipe de los Ingenios, ya que Cervantes tenía unos quince años más que él, la mitad poco más o menos de una generación.

Desde muy joven se aficionó al teatro y buscó la compañía de los autores y de los artistas, figurando ciertamente en las filas de aquellos mosqueteros del Corral de la Cruz o de la Pacheca que sembraban el terror o consagraban el éxito de las obras por sus pataleos o sus palmadas.

Desde muy joven empezó a escribir comedias para que las representase la que fue el primero y ruidoso amor de su juventud, la comediante Elena Osorio, conocida en sus poemas con el nombre de Filis.

Conocemosihoy detalladamente cuáles fueron los escandalosos resultados der aquellesiambrís.s.n Coqueta e infiel no sólo a su marido, director de compañía, sino a su propio amante, Elena fue zaherida agriamente en unas letrillas que corrieron por todos los círculos literarios del Madrid de entonces y tan grande fue el lío que se armó a continuación que intervino la justicia y Lope se vio desterrado a Valencia donde se unió a los escritores de teatro residentes allí y que capitaneaba a la sazón Guillén de Castro.

No crean Uds. que arrênpentido se fuese a orillas del Turia. Antes de marcharse, raptó a Isabel de Urbina con quien casó, olvidando en la villa y Corte a sus ruidosas conquistas. Más tarde, escribiendo, amontonando obras, novelas, poesías épicas o burlescas, como un vendaval que ningún obstáculo retiene, se alista en la Invencible Armada para conquistar Inglaterra. Mientras está en los buques prontos a zarpar, escribe la Angélica y no parece lamentar mucho el ingente fracaso naval de Feilpe II. Secretario del duque de Alba a quien ayuda en turbios compromisos licenciosos, vive en Toledo y en Alba de Tormes. Lo procesan por 
concubinato en el año 1596. Vive en Sevilla. Luego, se instala definitivamente en Madrid en la calle de los Francos que hoy lleva su nombre y en que han vuelto a reconstituir piadosamente la casa en que murió. Hasta las palomas torcazas. La visité hace muchos años y no pude ocultar la profunda emoción que uno experimenta al atravesar aquellas estancias modestas en que el gran poeta meditó, obró, murió. Allí se desvivió en el azar de la escena y en el frío amoroso de las cómicas. Allí, llegado a los cincuenta años, se ordenó de sacerdote con una fe candorosa y profunda que le hacian temblar las manos, cada mañana, al alzar a la blanca hostia que acababa de consagrar. Alli, a pesar de sus emociones sinceras, pero contrarias y sucesivas, se enamoró de Marta Nevares, la linda loca de los ojos verdes, que fue la última pasión de su vida; allí vivió de secretario, de inspirador amoroso y de alcahuete al duque de Sersa de quien recibió valiosos beneficios. Allí conoce el soplo halagüeño de la gloria académica. Allí le raptan a su hija predilecta Antonia Clara y de allí se va para el claustro lo que será su último consuelo y su tierna protectora, Sor Marcela de San Félix.

Se casó dos veces, como se sabe. Muerta Isabel, contrae matrimonio con doña Juana Guardo, hija de un opulento abastecedor de carnes, lo que le vale los flechazos más agudos de Quevedo y de Cervantes. No olvidamos a Micaela de Luján, viuda con siete hijos de los cuales-5 debían la vida al incansable creador.

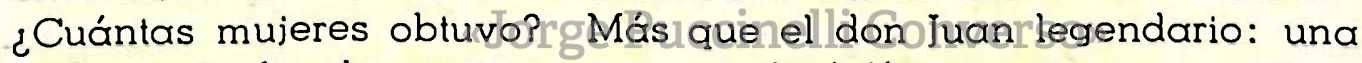
cadena $\sin$ fin de amantes que ponderó líricamente en una lista inacabable de poemas. Quince, veinte, treinta amores de trapicheo y picadura de tarántula. Burlador y burlado a la vez, necesitaba esa lucha contínua con el bello sexo para alimentar su producción dramática y trazar esos retratos de mujeres traviesas, audaces, finas y arrojadas que, en lucha eterna con el hombre, sabían utilizar todas las armas, no sólo de su belleza, sino de su ingenio y de su picardía. Suenan a lo largo de su obra aquellos nombres musicales -Filis, Marfisa, Camila, Lucinda, Gerardaque él convirtió en diosas paganas y en estrellas del firmamento teatral, y aquella Amarilis indiana cuyo nombre queda todavía por descubrir. Como se habla en Francia de las mujeres de Racine, se habla en España de las de Lope; sus figuras gentiles desfilan delante de nuestros ojos con las bizarras galas con que las vistió el poeta. 
Estrella, la de Sevilla, que se negó al rey don Pedro: Casilda, la encantadora labradora del lozano Peribañez; doña Inés del caballero de Olmedo y la deliciosa Laurencia de Fuente Oveiuna son las que encabezan aquella guirnalda interminable de protagonístas femeninas que debieron la vida al genio portentoso de nues. tro autor. Pero hay centenares de figuras guapas y sutiles que le deben la vida, que florecen en cada una de sus comedias y que murmuran a lo largo de ellas una canción melodiosa y gentil, cuyos ecos resuenan sin fin en nuestros oídos.

Como Alfredo de Musset, Lope amó a las mujeres, gozó con ellas, sufrió por ellas, traidor y traicionado a la vez, en ese vendaval erótico que menciona un crítico, redimido sin embargo, en sus traiciones y burlas, por una como ingenua sinceridad, una falta de cálculos y de maldad que nos permite perdonarle todas sus techo. rías amorosas.

No olvidemos que allí está la fuente inagotable de su numen teatral, lo que le permitió edificar un monumento $\sin$ igual que asombra a los siglos.

$\mathrm{Si}$ los españoles en general tienen una propensión inimitable a la improvisación -y hay ejemplos farnosos desde los autores desconocidos de los cien mil poemas del Romancero hasta Zorrilla-, nadie sin embargo le aventaja a Lope en esta materia.

Ya se conoce la anécdota famosa que cuenta Montalván. Una cofradía piådosáchabía encargado ab poeta una comedia de santos inédita en un plazo muy breve Lope convidó a Montalván a su casa para escribirla juntos, a razón de un acto y medio por autor. Montalván se quedó velando toda la noche para concluir con la mayor parte de su trabajo. Cuando, por la mañana, bajó al jardín para descansar un rato, encontró a Lope regando y éste le confesó que ya se había salido con la suya, había escrito un gran poema de no sé cuantos versos y se había cansado podando Y regando en su huertecillo.

En otra ocasión, nos dice Lope que veinte comedias suyas fueron escritas por él en un plazo de 24 horas, de las cuales algunas seis pecan contra la regla del nuevo clasicismo. Tres actos en un día, ¿por qué no? si sólo se cuenta el tiempo gastado en escribirlos. Alarde pueril de un gran autor capaz de una asombrosa improvisación y hazaña deportiva que repitió en su tiempo José Zorrilla y de la cual hubiera sido capaz nuestro gran Víctor Hugo.

No en eso reside el genio verdadero del poeta y es quizás de lamentar esa facilidad que tuvo él para emborronar cuartillas. 
Habiendo experimentado como lo hizo todas las alegrías y todos los dolores del hombre, si hubiera podido reflexionar con retención sobre ellas, mostrándose más severo para estos cohetes espontáneos que le brotaban de la mano, quizás nos hubiera dejado alguna figura imperecedera, prototipo de tal o cual particularidad humana, como el don Juan de Tirso, la Celestina o los inmortales don Quijote y Sancho de su malogrado rival, Miguel de Cervantes.

Examinemos ahora lo que nos queda de aquellos fuegos artificiales que alumbraron un medio siglo español.

Los límites de su teatro, imposible trazarlos definitivamente ¡quién va a contar los guijarros que acarrea un torrentel

Si nos atenemos a la confesión personal del autor, Lope escribió más de 1,800 comedias, 400 autos sacramentales, entremeses, loas, amén de todo lo que no pertenece al teatro.

No hay que fiarse del todo de lo que nos cuenta esa poderosa imaginación, a veces algo fanfarrona. Los títulos de comedias que han gustado distan mucho de llegar a mil y se conocen unas 462 comedias aproximadamente que se les puede atribuir, con sólo 38 autos. Ya es algo. Difícil tarea la de atribuir las obras más conocidas a veces a un autor célebre en una época en que no existía la propiedad literaria. Los dramaturgos robaban a plena mano las concepciones de sus contemporáneos. No les importaba un higo tomas una escena de una obra, otra de otra, refundir dramas ajenos y presentarlos como sacados de su propio magin. Ya se sabe que cuándo L6 6 e estrenabd, las compañías rivales mandaban a un espía a escuchar la obra para repetirla casí íntegra a los cómicos que se apoderaban de ellas. Mas tarde cundió la fama de Lope por todos los ámbitos, los autores extranjeros y particularmente los franceses, se enriquecieron con sus despojos, traduciéndolo sin mentar su nombre, despedazándole y utìizando la maravillosa mina de situaciones dramáticas que había dejado ese inagotable creador.

En aquel Himalaya de obras se pueden dividir las comedias profanas y las religiosas.

Lo esencial de las primeras estriba en las comedias en que domina el elemento histórico sacado sea de la historia de España, sea de la historia extranjera antigua. y moderna, o de las fuentes caballerescas.

Las comedias romanescas que nos vienen de las novelas: italianas y españolas. 
Y las comedias de capa y espacia que trazan un vivo retrato de las costumbres de la época.

Para sus comedias históricas, Lope se apoderó de la historia universal y de la geografía del universo entonces conocido. Si hubiera vivido en nuestros días, algunas de sus obras hubieran pasado en la Luna.

Pero supo antes de todo dar a su drama nacional, no el color verdadero de la realidad, sino el más verosimil. Supo sacar de las tradiciones populares los tipos más originales en que se re. conoció en seguida toda una nación.

Adivinó maravillosamente el hondo sentido de su historia y lo interpretó exactamente.

Podemos citar en esta categoría: los Tellos de Meneses, los Novios de Hornachuelos, Peribañez o el Comendador de Ocaña, la Niña de Plata, la Estrella de Sevilla, El Mejor Alcalde el Rey, de la cual hice ya una refundición realizada, en el año 43, en el Teatro Sarah Bernhardt de Poris por elmagnífico autor y director de entonces que se llamabd Charles Dullín.

Nadie como Lope para resucitar inspirándose en los anales patrios, que las galas de su poesía embellecen, a un héroe, un hombre, un hecho, una época: España toda, desde "El último Godo" de la pérdida de España, hasta "El Marqués de las Nevas" de la época de Felipe IV. Una España rediviva que se quedará eternamente en nuestra memoriactal comó nos la pinta, tal como la pintó en sus cuadros famosos. Diego Velásquez.

No necesita gran cosa Lope para enderezar la trabazón de todo un drama, una canción captada en las eras, una serranilla, una seguidilla, un refrán, sus versos de leyenda popular.

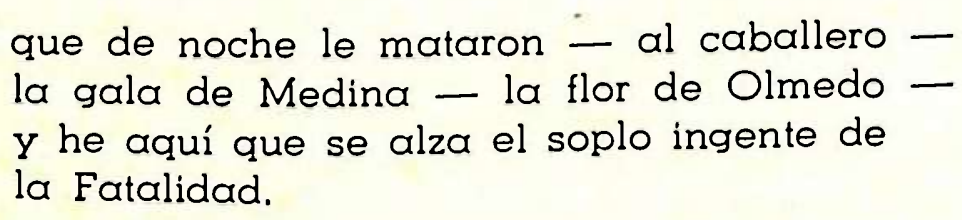

Un escritor francés conocido, Jules Romains, pretendió inventar, cincuenta años ha, una teoría literaria que llamó el unanimismo. Pretende que cualquier acto, a veces el más insignificante de los hombres, produce resonancias inesperadas en todos los otros y que nadie se puede librar del más pequeño gesto, del más leve pensamiento de los demás. El alma colectiva sólo es el gran 
protagonista de la historia. Se dobla delante de ella el alma individual sea la de los mayores prohombres.

Pues, Lope había ya descubierto esta gran verdad cuando dio su obra maestra: Fuenteovejuna, drama de rebelión colectiva, obra democrática al par que monárquica en que se expresa la alianza del pueblo y de los Reyes Católicos para abolir el excesivo poderío de las órdenes militares.

En Fuenteovejuna la colectividad hecha protagonista se lanza contra el Maestro de Calatrava, colmada la medida de la paciencia. Lope traza el drama de todo un pueblo en una obra claramente revolucionaria pero monárquica también, como se entendía en los albores del siglo XVII.

Suprimir el final y la aparición de los reyes justicieros, como se hizo en la adaptación soviética rusa de hace unos 20 años, es desvirtuar el verdadero carácter del autor y de su tiempo.

Un insigne escritor francés, mi amigo Jean Cassou, y yo, dimos una adaptación de Fuenteovejuna, el 38, en el Teatro del Pueblo de París, y de allí nació en la Francia contemporánea la boga del teatro español. Pero respetamos el pensamiento del poeta y nadie vio en el desenlace un intento de exaltación monárquica, sino la reacción sana y arrolladora del pueblo delante de la injusticia.

Sobresalió aun más Lope de Vega en la comedia de capa y espada, que es la verdadera comedia nacional, juspirándose en las costumbres de la clase media que pinta a maravillas. Claro es que las poetiza en "un renredb a veces complicado" y romanesco, pero ingenioso y nutrido por el movimiento incesante de la intriga y de los personajes. Quid proquos, burlas, disfraces, sustituciones de personajes, reconocimientos, parodias de los amores de los amos por los criados astutos que desempeñan el papel de graciosos, descripciones animadas de las escenas y de los sitios populares, tales son los elementos básicos de la comedia. Nos suministra, bajo la pluma de Lope, el cuadro más vivo, más pintoresco, más completo de la vida española en Madrid, en Toledo, en Valencia y en Sevilla. Renace toda una sociedad curiosísima con su encanto incomparable. Vuélvase a leer las Flores de San Iuan, El anzuelo de Fenisa, El acero de Madrid, La hermosa fea, El perro del hortelano, La noche de San Juan, El dómine Lucas, y El villlano en su rincón que voy a dar en París como una comedia-ballet y se verá cómo surge de esa lectura un tiempo pretérito que nos conmueve y nos embelesa por sus fragancias siempre atractivas. 
En estas obras se revela el hombre de teatro completo, que lo sabe todo, lo maneja todo, lo pinta todo con el color de la ilusión teatral y nos lleva a un mundo de ensueño y de belleza en que nos olvidamos del mundo de barro y de tristeza en que estamos hundidos.

Otro alarde de Lope, para mi extraordinario: aquella co. media pensada, hecha, elaborada, escrita para el pueblo, para los mosqueteros de pie en el corral, Lope le da un estilo de una destreza y de una ciencia insuperables. Todas las formas de prosodia están aquí fijadas definitiramente: el romance para la exposición, la redondilla y la quintilla para las escenas amorosas, el soneto para quien espera, la décima para las quejas, todo esto afirmando una variedad, una maestría extraordinaria, una orquesta poética manejada y dirigida por un maestro de la batuta de oro.

Los elementos que encierra esta obra magna, Lope los encontró ya en sus predecesores: la mezcla de lo trágico y de lo cómico, el gracioso, el tema general de las intrigas, la versificación. Pero fue él quién fijo definitivamente las normas de la comedia clásica española.

No se preocupó de los inteligentes, de los científicos, sino do este público a quien gusta una psicología somera, caprichosa, divertida, mucho movimiento como en la comedia del arte italiano, visiones familiares de la vida cotidiana embellecida por una fantasía risueña.

Bien lo dice en su Arte nuevo de hacer comedia. Un arte nuevo sin preocupaciones culturales muy altas que busca antes de todo el aplauso colectivo, el aplauso comercial, la invasión del teatro que llena las taquillas.

Pero su genio se impuso a su intento. Prisionero de su genio, Lope no podía faltar de inspiración, de gracia, de poesía. No podía rebajar el tono de su diáfana, tersa y elegante facilidad.

Así nos dio aquella cantera abundante en que las posibilidades y aciertos parciales, cuando no las completas realizaciones, compensan las caídas y los embrollos.

Vértigo de intriga, una vez más, y canto cristalino de la poesía del alegre vivir, del optimismo esencial, de la plenitud de amor y de acción del autor.

Después de la muerte apoteósica de Lope, se hizo el silencio sobre el valor extraordinario de su aportación al teatro. Vino la época de Calderón y al poeta de la España del Siglo XVII sucedió el poeta del cielo y de los problemas metafísicos del hombre. 
El siglo XVIII reaccionó en pro de Calderón. Se inspiró en éste el teatro francés. Al reaccionar el romanticismo alemán contra el academismo francés, se olvidó a Lope para enaltecer al autor de "La devoción de la cruz". En Inglaterra, Shelley profesa un fervor poético por Calderón.

Pero, a mediados del Siglo 19, se perciben en fin claras aproximaciones a Lope y desde entonces no deja de resplandecer la gloria de este Fénix que volvió a ocupar el primer plano que siempre será el suyo, porque nunca el arte teatral nos dio un autor tan íntegramente sometido a él y tan repleto de posibilidades infinitas.

Se suele comparar frecuentemente Lope a Shakespeare, considerando que son aquellos dos autores las cumbres más importantes del teatro universal.

No cabe duda en que el genio inglés ha creado personajes más típicos, más hondos que tienen ya valor de símbolo y que no se pueden borrar de nuestro recuerdo tal como el celoso, el ambicioso, el mercader ávido, etc.

Pero Shakespeare, universalizándose, no dio de su Inglaterra y de su tiempo la imagen que Lope nos da, en su abigarrada complejidad, de la España del Siglo de Oro. En su obra reviven la corte de los Reyes austriacos, los privados, la juventud turbulenta y pundonorosa de palacio, las fiestas brillantes de la corte, las damas bizarras y gallardas con sus don Juanes embebecidos, la chusma de los criados apicarados yede las doncellas astutas, los pedantes y los malos poetas, y el campo castellano con sus aldeanos valientes y esforzados, sus lindas zagalejas, el encanto de las fiestas entre florestas y bosques, la nobleza ingenua de los vecinos de Fuenteovejuna, el amor a la vida apacible que cantó Fray Luis de León, lejos del mundanal ruido.

Además, si volvemos a la comparación con Shakespeare, tenemos que decir que la obra formidable, pero reducida del inglés, puede verse aplastada por aquel Aconcagua de la obra ingente de Lope. Se ha calculado que por una página de Shakespeare, Lope ha escrito más de tres comedias en las cuales, entre descuidos y errores, brillan trozos de poesía centellante, escenas exquisitas, detalles de psicología refinada, de tal modo que, al fin $y$ al cabo nuestro Lope creó más riquezas que el dramaturgo británico.

Lástima e injusticia es que el teatro de Lope, visión deslumbradora de su España, no haya pasado con la fuerza debida: las fronteras de su país. 
Sin embargo el mundo todo, y sobretodo nuestros autores franceses del Siglo 17 y 18 vinieron a cavar en esta inmensa cantera de situaciones teatrales, de intrigas, de enredos sutiles y robaron a nuestro poeta sin confesar de dónde sacaban tantos tesoros de sutileza y de poesía.

Claro es que, desde siempre, se decia: Es de Lope, para expresar una cosa de acierto y de belleza.

Pero nosotros, los lopistas, queremos resucitar hoy dia, en homenaje al dueño imperecedero de las tablas españolas, esta oración que repetian sus discipulos en el momento de su mayor gloria, subrayando la potencia nunca igualada de su genio fecundo y torrencial:

Creo en Lope todopoderoso, creador del cielo y de la tierra.

Y con esto, todo queda dicho.

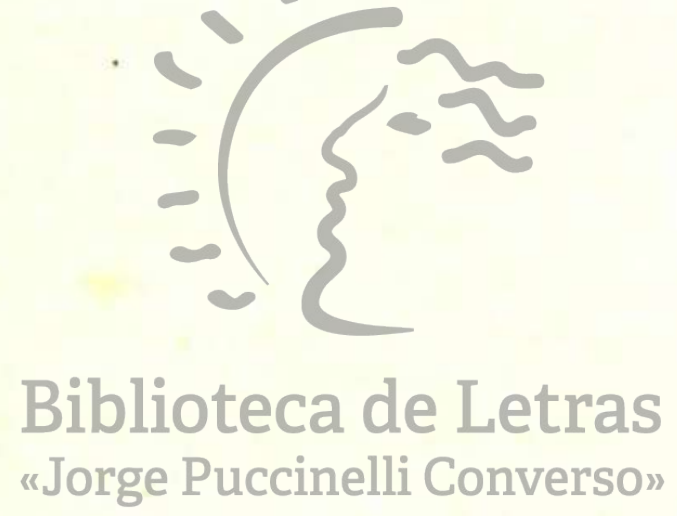

Jean Camp

Profesor en la Universidad de Aix en Provence.

Miembro corresponsal dèl Instituto de Francio.

Roquefort les Pins. (A. N.).

Froncia. 